\title{
Martin Böhnert: Methodologische Signaturen. Ein philosophischer Versuch zur Systematisierung der empirischen Forschung des Geistes von Tieren
}

\author{
Mentis: Paderborn 2020, XVIII + 342pp., € 79,00, ISBN: 9783957437112
}

\section{Julia Gruevska ${ }^{1}$}

Published online: 25 November 2021

(C) The Author(s) 2021

Contemporary debates about $\mathrm{CO}_{2}$ emissions, climate change, as well as ethical and political concerns about consumerism, make philosophical questions about animals more important than ever. Through reflection on these issues, in recent years, a so-called 'animal turn' took place in certain disciplines in the humanities and even led to a new disciplinary field called '(human-) animal studies'. In philosophy, animals are perhaps most frequently discussed in animal ethics and philosophy of biology (as model organisms) as well as in the smaller field of philosophical anthropology, which inquires into the distinction between humans and animals and their relation to the world. Arguably the most prominent philosophical treatment of the topic 'animals' addresses the question of whether-or to what extent—animals have minds.

But animal philosophy can also be approached in a quite different theoretical way, as Martin Böhnert's book Methodological Signatures: A Philosophical Attempt to Systematize the Empirical Research on the Mind of Animals shows. While elaborating a method to compare different approaches of animal studies, Böhnert's book is not to be understood as a philosophy of animals, but rather as a work located more generally in philosophy of science. It nevertheless also makes a significant contribution to animal philosophy by investigating the question of how we gain empirical knowledge of animals.

Böhnert's analysis is very detailed and his book is well thought out, intelligent and promising. It presents for the first time a work that applies the so-called 'methodological signature' approach ('methodologische Signaturen') to research on cognitive abilities of the animal mind and then extends this approach by identifying 'methodological gaps' ('methodologische Leerstellen'). Methodological signatures are understood as a scientist's or scholar's personal approach to an investigation. They emerge from the explicit decisions of the investigator. In the case of animal research these can be, among others, the choice of the test animal, the setting of experiments or observation, the methods of investigation as well as epistemic values. Methodological gaps are understood as the implicit decisions

Julia Gruevska

Julia.Gruevska@uni-jena.de

1 Geschichte und Philosophie der Naturwissenschaften, Friedrich-Schiller-Universität Jena, Berggasse 7, 07745 Jena, Germany 
investigators make, which result from the attitudes they adopt. Beliefs, dispositions and other non-expressed methodological decisions are examples of such gaps, which, according to Böhnert, must be identified by philosophers of science. For Böhnert these gaps are crucial for understanding research investigations because they constitute the underlying structure of research approaches.

Böhnert's method, which will be discussed later in this review, arose from his involvement in the interdisciplinary research group "Animal-Human-Society" (LOEWE, 2014-2017), which focused on the interdisciplinary investigation of animal-human relationships in history and society. In this context he has co-edited three volumes on this topic, dealing with the methods and programs, maxims and consequences, and milieus and actors in the philosophy of animal research (Böhnert, Köchy, Wunsch 2016a; 2016b; 2018).

Since the knowledge we gain from animals is almost always based on empirical research, a philosophical analysis is confronted with three challenges, that, according to Böhnert, can be dealt with by using the concept of methodological signatures: These signatures allow the systematic comparison of research approaches based on (1) their fundamental methodological presuppositions, (2) their ontological presuppositions, namely that it is almost impossible to fill the gap in the subject-object-relationship between humans and animals with respect to both experiments and observations, and (3) their epistemological presuppositions and the question of how we can know anything about animal cognition when we hardly know anything about the human mind. All these challenges are ultimately interdependent. Böhnert's first step is therefore to reconstruct the epistemic framework that guides research practices and knowledge acquisition. This is examined by following two main questions:

(1) How do we acquire knowledge concerning the question of whether and what cognitive abilities animals have?

(2) Under which epistemic conditions does empirical animal research gain knowledge about the cognitive abilities of animals?

These questions are addressed in six chapters. In Chapter 1, Böhnert locates the studies of animal mind in the interface between ethology and comparative psychology. In Chapter 2 , he then discusses contemporary research on the animal mind, highlighting in particular the studies of Christophe Boesch and Michael Tomasello on collective intentionality in chimpanzees. Here, Böhnert is primarily concerned with the plausibility of the respective scientific findings and the vague notion of plausibility itself. In Chapter 3, Böhnert introduces his methodological approach, namely that of methodological signatures and gaps. In light of this framework, in Chapter 4, Böhnert examines studies of animal minds in the debate between the founding fathers of comparative psychology, George Romanes and C. Lloyd Morgan. Böhnert compares the taxonomic systems of these two scientists, their metaphysical presuppositions, and analyzes their methodologies against the background of their views of objectivity, validity, and reliability. In Chapter 5, Böhnert highlights 'methodological gaps' in the study of animal minds in order to then, in Chapter 6, systematically compare the 'methodological signatures' of Boesch and Tomasello. In what follows, I will first focus on the method Böhnert develops and then briefly discuss the case studies he presents.

Böhnert's approach of methodological signatures has been developed by the philosophers Kristian Köchy and Matthias Wunsch and, by including components from feminist philosophy of science, Helen Longino. Like Longino, Böhnert rejects the idea that looking 
at data yields a "seamless web of knowledge" (Longino 1987, 62) and rather tries to be as close as possible to scientific practice in order to understand a particular field. In this way, it is also possible to recognize what exactly a field's unconfirmed and fundamental assumptions-like attitudes, dispositions, beliefs, or as Ludwik Fleck puts it, thought stylesare and how they affect the investigation of researchers. Böhnert thus extends Longino's idea by integrating Karin Knorr-Cetina's knowledge-cultures approach, as this allows the consideration of situational views. Once the different kinds of assumptions underlying a research approach have been identified, these can then be systematically compared. To make such a comparison feasible, Böhnert introduces the notion of methodological signatures, which he also identifies by methodological gaps.

Those gaps- "Leerstellen"- originally are part of a theory of literary aesthetics developed by Wolfgang Iser (1976). They should make the detection of unnamed assumptions possible. Just as in Iser's so called Reception Theory, where the reader is an unnamed gap in every literary text, Böhnert aims to identify central gaps in research approaches. The more gaps that can be identified in research approaches-Böhnert explicitly refers to research approaches rather than, like Köchy and Wunsch, to research programs - the more accurate is the identification of methodological signatures. The aim is thus to uncover individual gaps and their interrelations. In other words, in order to identify a research approach, the totality of decisions made by the researcher must be elucidated. Methodological signatures can thus be viewed as a composite of various expressed as well as of unexpressed characteristics (gaps) in research approaches. They are a manifestation of choices made by researchers. The case of C. Lloyd Morgan provides a striking example of this. Böhnert notes that there are not one but two signatures inherent in Morgan, one that manifests itself in his early works and one that emerges in his late works. Böhnert is able to identify these signatures by examining the gaps, that is, in particular, Morgan's scientific ethos and attitude, and he uncovers a crucial discrepancy between Morgan's early and late approaches to research. In fact, while Morgan's early work underlies a reductionist materialism that believes only in observable motion in space and time, he later took the view of scientific monism, which was accompanied by an introspective method. In this way, by identifying relevant signatures, Morgan's different research approaches can be compared with one another and with others approaches, such as that of George Romanes.

Explicit and implicit characteristics are made, Böhnert states, by the selective decisions researchers make. These decisions take place prior to any empirical research, since it is only through these decisions that the respective subject area is determined in a specific way. According to Böhnert, it is the task of philosophy as well as of empirical research to make these decisions, which ultimately determine the specific field and approach. Regarding Böhnert's field of exploration, namely the research on cognitive abilities of animals' minds, he shows that in addition to the methodological characteristics, the material, spatial and conceptual aspects must also be considered. According to him, these are all interrelated. All these considerations ultimately determine the methodological approach and vice versa: Research places must be perceived as multidimensional entanglements of material, spatial and conceptual determination. What place can be considered as a research area, how is a research place constituted, and how are they conceptually composed? In a similar way, the animals that are observed and tested as well as the researchers' ideals must be regarded as embedded in such a multidimensional framing.

With respect to the scientific ideal, we can examine scientists' epistemic virtues, verbal realization and self-reflections. However, these aspects are constantly accompanied by the problem how to relate humans and animals, experimenter and research object. Böhnert assumes, on one side, that such fundamental ideals are not only part of a discussion that 
begins in the aftermath of empirical research but are, at least implicitly, already part of the research itself. And on the other side, he argues that the results and answers to the question about animal cognitive abilities depend on metaphysical-ontological assumptions about the subject area, the methodological settings of the procedure, the investigative methods and the spatial-conceptual context of the research locations. They also depend on the methodological-conceptual framework in which the preferred reference animal is studied as well as on the epistemic-conceptual structure of the underlying research ideal. These are all selective choices the researchers make and which are left as signatures within their research. Böhnert is aware that he too makes choices in his research and indicates that he does not fully capture the series of gaps insofar as there is the possibility that they also evolve dynamically.

Böhnert also emphasizes context sensitivity as a central aspect to better understanding not only contemporary but also historical research approaches. According to Böhnert, all these fundamental presuppositions, which can be uncovered by using his methodological approach, culminate in the concrete research situation.

The first case study he discusses to illustrate his approach is that of the two (former) heads of the Max-Planck-Institute for Evolutionary Anthropology (Leipzig, Germany), namely Tomasello and Boesch's investigations into the question of collective intentionality. Böhnert reconstructs the research of both scientists and compares them. Based on this reconstruction he identifies divergent aspects, such as lab- versus enclosure-based research, a differentiation between ethology and comparative psychology, collective versus individual research and the terminological usage of 'animal' versus 'animals'.

The second case study is the well-known dispute between the so-called founding fathers of comparative psychology Morgan and Romanes. Böhnert does not assume that both animal psychologists in their work in comparative psychology were simply arguing about a set of problems that were present at the time, but that they were dealing with three methodological gaps in the study of animal mind. These include (1) the taxonomy of the mental capacities to be studied in animals, (2) the metaphysical presuppositions of the study of animal minds, and (3) the methodological procedures of this research.

Böhnert warns, that not thematizing the signatures as well as not contextualizing them often means creating or reproducing misunderstandings of research approaches. Another advantage of this approach is that it brings together theories from different disciplinary fields - theory of science, feminist theory, and literary theory - within a productive framework for philosophy of science. To do so, the author carefully develops the individual arguments for and applications of his approach throughout his book, while subjecting them to critical epistemological analyses. In this way, he elaborates his assumptions and propositions precisely through comparison with or in opposition to philosophical concepts such as Ludwik Fleck's thought styles or Imre Lakatos' methodology of scientific research programs. However, the question remains whether it is possible to actually compare (different or similar) research approaches across epochs as Böhnert envisions at the beginning of his book. From a philosophical perspective, this is certainly a common approach, but from a historical perspective, Böhnert's aim of comparison might not be fully achievable, no matter how well the research context has been reconstructed. In particular, historical notions, presuppositions etc. cannot be easily detected insofar as, for example, concepts and terminologies are often connected with other semantic fields that are strongly rooted in their specific historical contexts. It is nevertheless worthwhile to further test the method of methodological signatures and gaps, especially to find out its virtues but also limitations when it comes to temporal bridging. 
Finally, as the study of animal minds makes it clear once again, it is worth pointing out that, besides empirical research, philosophy too has its rightful place in the discourse about animal studies. Böhnert's book shows this in paradigmatic fashion and can be recommended especially to philosophers and historians of science and the broader audience of (human-)animal studies. I hope that we will also see Böhnert's 'signature' in new research projects and that his stimulating approach will inspire future research, not only in the area of animal philosophy.

Funding Open Access funding enabled and organized by Projekt DEAL.

Open Access This article is licensed under a Creative Commons Attribution 4.0 International License, which permits use, sharing, adaptation, distribution and reproduction in any medium or format, as long as you give appropriate credit to the original author(s) and the source, provide a link to the Creative Commons licence, and indicate if changes were made. The images or other third party material in this article are included in the article's Creative Commons licence, unless indicated otherwise in a credit line to the material. If material is not included in the article's Creative Commons licence and your intended use is not permitted by statutory regulation or exceeds the permitted use, you will need to obtain permission directly from the copyright holder. To view a copy of this licence, visit http://creativecommons.org/licenses/by/4.0/.

\section{References}

Böhnert, M., Köchy, K., \& Wunsch, M. (2016a). Philosophie der Tierforschung, Band 1: Methoden und Programme. Freiburg i.Br.: Karl Alber Verlag.

Böhnert, M., Köchy, K., \& Wunsch, M. (2016b). Philosophie der Tierforschung, Band 2: Maximen und Konsequenzen. Freiburg i.Br.: Karl Alber Verlag.

Böhnert, M., Köchy, K., \& Wunsch, M. (2018). Philosophie der Tierforschung, Band 3: Milieus und Akteure. Freiburg i.Br.: Karl Alber Verlag.

Iser, W. (1976). Der Akt des Lesens. Theorie ästhetischer Wirkung. München: Wilhelm Fink Verlag.

Longino, H. E. (1987). Can there be a feminist science? Hypatia, 2(3), 51-64.

Publisher's Note Springer Nature remains neutral with regard to jurisdictional claims in published maps and institutional affiliations. 